\title{
Neuropsychological evaluation of mild head injury
}

\author{
MASSIMO GENTILINI, ${ }^{*}$ PAOLO NICHELLI, ${ }^{*}$ RUDOLF SCHOENHUBER, ${ }^{*}$ \\ PAOLO BORTOLOTTI, ${ }^{*}$ LUIGI TONELLI,$\dagger$ ANGELO FALASCA,$\dagger$ GIAN A MERLI $\dagger$
}

From the Clinica Neurologica dell'Universita' di Modena* and Divisione di Neurochirurgia del Policlinico, $\dagger$ Modena, Italy

SUMMARY Neuropsychological deficits following mild head injury have been reported recently in the literature. The purpose of this study was to investigate this issue with a strict methodological approach. The neuropsychological performance of 50 mildly head injured patients was compared with that of 50 normal controls chosen with the case-control approach. No conclusive evidence was found that mild head injury causes cognitive impairment one month after the trauma.

Effects of head injury on mental functions have usually been studied in patients with severe trauma. Studies on the consequences of mild injury are much rarer, in spite of the fact that these patients frequently complain of difficulties in concentration and memory and poor intellectual efficiency.

Gronwall and Wrightson ${ }^{1}$ found reduced efficiency in 10 patients with mild head trauma and subjective post-concussion syndrome as revealed by the PASAT test (which requires the patient to sum a series of numbers given at a rapid rate) in comparison to the performance of a patient group with head injury of the same degree but without the subjective syndrome. Altered PASAT scores were found in the initial phase, and returned to normal within 30-35 days. In 1981 Rimel $e t a^{2}$ published an exhaustive analysis on 538 patients with mild head injury defined on the basis of the following parameters: loss of consciousness for less than $20 \mathrm{~min}$, Glasgow Coma Scale (GCS) values ranging between 13 and 15 , length of hospitalisation less than 48 hours. Follow-up was performed on 424 patients 3 months after the trauma: of these $79 \%$ complained of persistent headaches, $59 \%$ had memory loss, and $34 \%$ had not resumed occupational activities. More precise results on a subgroup of 70 patients from this group were subsequently reported by Barth et al, ${ }^{3}$ who used the Halstead Neuropsychology Battery, the Wechsler Scale of Intelligence and Memory, and the Wide Range Achievement Test. The Halstead Battery showed moderate to severe impairment in 22 patients, a mild deficit in another 22 , and a mini-

Address for reprint requests: Dr P Nichelli, Clinica Neurologica, Via Del Pozzo, 71 I-41100 Modena, Italy.

Received 30 May 1984. Accepted 21 July 1984 mal impairment in 26. Cognitive deficits did not seem related to the duration of loss of consciousness, post-traumatic amnesia, and the presence of sensory and motor deficits. The correlation between Halstead index, psychological disturbances, and difficulty in resuming occupational activities were significant, but at a low level. However, an adequate control group was not used in the comparison.

The purpose of this study was to evaluate neuropsychological deficits in a population of patients whose head injuries were defined as mild according to precise criteria and whose performances were compared to those of a control group closely matched for age, educational level, and socioeconomic status with the study group.

\section{Methods}

Fifty consecutive mild head injury cases, referred to the Division of Neurosurgery of the Policlinic of Modena from November 1982 to September 1983, were studied. Criteria for admission to the study were loss of consciousness for less than $20 \mathrm{~min}$, an initial score on the Glasgow Coma Scale $^{4}$ of 13 to 15 , hospitalisation less than 3 days, negative neurological examination upon admission and discharge, and no medical complications. Patients younger than 13 or older than 75 years were excluded. Fifty controls were chosen one by one by each patient from his/her spouse, relatives, friends, and schoolmates (case-control pairing).

Table 1 Demographic features of the two experimental groups

\begin{tabular}{llllllll}
\hline & Sex & \multicolumn{2}{l}{ Age (yr) } & & \multicolumn{2}{l}{ Education } \\
\cline { 3 - 4 } \cline { 6 - 7 } & & & $\bar{x}$ & $S D$ & & $\bar{x}$ & $S D$ \\
\hline Patients & $19 \mathrm{f}+31 \mathrm{~m}$ & $35 \cdot 38$ & $19 \cdot 11$ & & $7 \cdot 60$ & 3.46 \\
Controls & $27 \mathrm{f}+23 \mathrm{~m}$ & $33 \cdot 78$ & $17 \cdot 12$ & & $7 \cdot 96$ & $3 \cdot 13$ \\
\hline
\end{tabular}


In the patients tests were always performed one month after trauma. Demographic features of the experimental groups are reported in table 1 .

The neuropsychologic battery consisted of six tests evaluating attention, memory, and intelligence.

(1) Selective attention test: The subject was presented with a matrix of 13 lines with 10 numbers each (from 0 to 9 in random order) and was asked to mark as fast as possible the number corresponding to that indicated at the top of the matrix. The test was repeated again twice, reproposing the same matrix and asking the subject to mark two and then three digits. The score took into account the number of correct answers provided in the three matrices in a maximum time of $45 \mathrm{sec}$ per matrix.

(2) Digits forward test: The subject was asked to repeat progressively longer lists of digits. For each length, beginning with that of two numbers, two lists were administered; 1 point was given for the first list of each length correctly repeated and an additional 0.5 point if the second list was also repeated correctly. ${ }^{5}$

(3) Word recognition test: The subject was presented with 60 words, one at a time ( 30 words with a high associative value and 30 words with a low associative value), written on a card to be read by the subject. Immediately afterwards the same words were presented again one at a time in a random order, intermingled with an equal number of distractor items, and subjects were asked to say which words they had already seen (yes-no recognition procedure). Retention performance was measured by calculating the $d$, an unbiased estimate of discriminability ${ }^{6}$ using the percentage of hits (correct "yes" responses) and false alarms (incorrect "yes" responses).

(4) Buschke's test: ${ }^{78}$ This is a verbal learning test on a list of 15 words, according to the technique of "selective reminding" proposed by Buschke. The list was first read once at the speed of one word every $2 \mathrm{~s}$ and the subject was asked for an initial partial recall. In each of successive trials the examiner repeated only those words not recalled from the previous trial. This procedure continued until the subject gave two consecutive recalls of the entire list or for a maximum of 10 trials. For each subject the learning curve, plotted as number of words recalled on successive trials, was examined. These curves were found to be fitted by a linear regression of the type $y=a+b x$, where $y$ is the number of words correctly recalled, $x$ is the number of the trial, $b$ is the regression coefficient, and $a$ is the intercept on the ordinate at $x=0$. This line being obtained, the theoretical number of trials required to recall the entire list $(N)$ was calculated for each patient by the formula $\mathbf{N}=(15-\mathbf{a}) / \mathbf{b}$. $\mathbf{N}$ values constituted the score by which the performance of each single subject was evaluated.

(5) Working memory test: Four cards corresponding to the four suits (hearts, diamonds, clubs, and spades) were layed down on a table. The subject was told to draw cards one by one as quickly as possible and to place them face up below the corresponding suit, while naming the number and suit of the card classified immediately before. The test was preceded by warming-up trial with 10 cards. The score took into consideration the number of cards correctly classified in one minute.

(6) Raven test: Raven Progressive Matrices" were used. The score was the number of correct answers within the time limit of $30 \mathrm{~min}$.

\section{Results}

Table 2 shows means and standard deviations of patients and normal controls for the six tests. Mean differences between pairs of patients and their matched controls are also reported.

For all tests, except for the Buschke learning task, the higher the score the better the performance. These latter scores were therefore transformed into their reciprocal values: in this manner performance on different tests were more easily comparable and furthermore the data spread more closely approached a normal distribution. Multicovarianceanalysis was performed on the standardised score of the six neuropsychological tests by means of Hotelling $t$ test. This gave a value of $\mathrm{F}=1 \cdot 1809$ o that with 6 and 44 degrees of freedom was not significant. Thus none of the multiple comparisons 1 proved to be significant.

These kinds of multicovariate analysis are particuê larly suitable for analysing differences between groups when subjects are examined by more than one test, in that the same degree of protection against type-1 errors as that for the general analysis is maintained for each comparison. However, enhanced protection on the one hand, corresponds to diminished power of the method. Thus we repeated the same comparisons by means of six univariate analyses. In this manner the performance of patients with mild head injury was found to be significantly lower than that of controls on the selective attention test $(F=5 \cdot 15, \mathrm{df}=1 / 49, \mathrm{p}<0.05)$.

Table 2 Mean and standard deviation (in parenthesis) of patients and controls in the six tests and difference from the mean

\begin{tabular}{|c|c|c|c|c|c|}
\hline \multirow[t]{2}{*}{ Test } & \multicolumn{2}{|c|}{ Patients } & \multicolumn{2}{|c|}{ Controls } & \multirow[t]{2}{*}{ Mean difference (original scale) } \\
\hline & $\bar{x}$ & $S D$ & $\overline{\boldsymbol{x}}$ & $S D$ & \\
\hline $\begin{array}{l}\text { Selective attention } \\
\text { Digits forward } \\
\text { Word recognition (d') } \\
\text { Buschke's test } \\
\text { Working memory } \\
\text { Raven }\end{array}$ & $\begin{array}{r}49 \cdot 76 \\
5 \cdot 58 \\
1 \cdot 34 \\
15 \cdot 95 \\
14 \cdot 70 \\
29 \cdot 30\end{array}$ & $\begin{array}{r}(9.00) \\
(1.34) \\
(0.54) \\
(16.67) \\
(6.38) \\
(10.47)\end{array}$ & $\begin{array}{r}52 \cdot 02 \\
5 \cdot 83 \\
1 \cdot 43 \\
14 \cdot 21 \\
15 \cdot 38 \\
30 \cdot 82\end{array}$ & $\begin{array}{r}(5.61) \\
(1.48) \\
(0.60) \\
(14.38) \\
(5 \cdot 21) \\
(9.25)\end{array}$ & $\begin{array}{l}2 \cdot 26 \\
0 \cdot 25 \\
0 \cdot 08 \\
0 \cdot 02 \\
0 \cdot 68 \\
1 \cdot 52\end{array}$ \\
\hline
\end{tabular}




\section{Discussion}

Long term neuropsychological outcome of severe closed head injury has become of increasing concern to neurosurgeons as advances in management has led to reduced mortality. A few recent publications have emphasised social and economic drawbacks caused by cognitive deficits following even mild concussion. ${ }^{12}$ Indeed, in spite of the fact that most patients who have suffered minor head trauma are discharged with a negative neurological examination after a short period in hospital, recover rapidly, and soon return to work, some of them continue to complain of symptoms such as headache, dizziness, loss of memory and concentration, and behavioural changes.

There are different opinions on the physiopathological mechanisms underlying these symptoms. Some authors, while emphasising the striking similarity between complaints after minor head injuries to those found in non-traumatic neuroses, seem to suggest that they represent a conversion reaction to anxiety caused by the trauma, ${ }^{11}$ while others maintain that anxiety and neurosis may follow cognitive deficits caused by a cerebral damage.'

Experimental models ${ }^{1213}$ have shown that acceleration-deceleration can provoke axonal tears and degeneration especially in the brainstem. The finding of altered brainstem-evoked potentials after concussion can be considered as indirect evidence of this mechanism, ${ }^{14-16}$ which is likely to be present in all trauma from mild to severe. ${ }^{17}$ Axonal degeneration in the brainstem would be expected to have a disruptive effect on cortical arousal and hence on cognitive performances.

Several neuropsychological investigations have been carried out over the past few years to evaluate cognitive functions in mild head injured patients, but unfortunately not all of them took into consideration the methodological constraints which are implicit in these kinds of studies: namely the need for a clear definition of which head injuries can be considered mild, the precise timing of examination after the trauma, and the criteria for selection of a normal control group.

This study concerned a neuropsychological investigation of mild head-injured patients one month after the trauma. Concussion was defined mild according to the same criteria adopted in a group of recent similar studies. ${ }^{2318}$

Patients' performances were compared with those of a control group chosen by means of a case-control pairing. In this manner not only age and educational characteristics were closely matched but possibly also social habits and environmental factors (such as alcohol consumption), which may weigh on neuropsychological scores and on the risk of head concussions. In spite of a general trend toward lower performances, head injured patients did not have significant impairment when the two experimental groups were compared with the appropriate statistical methods. It is still possible that a cognitive deficit may be limited to a subgroup of patients, for instance those complaining of subjective symptoms. However from this study it can be reasonably concluded that, if there is structural damage after mild head injury, it generally recovers from the neuropsychological standpoint within one month after the trauma.

We thank Professor P Faglioni and the "Centro di Calcolo" of the University of Modena for their very helpful advice. We are also indebted to Professor E De Renzi for his advice in preparing this manuscript.

\section{References}

' Gronwall D, Wrightson P. Delayed recovery after minor head injury. Lancet 1974;2:605-9.

${ }^{2}$ Rimel RW, Giordani B, Barth JT, Boll TJ, Jane JA. Disability caused by minor head injury. Neurosurgery 1981;9:221-8.

${ }^{3}$ Barth JT, Macciocchi SN, Giordani B, Rimel R, Jane JA, Boll TJ. Neuropsychological sequelae of minor head injury. Neurosurgery 1983;13:529-33.

4 Teasdale G, Jennett B. Assessment of coma and impairment of consciousness. A practical scale. Lancet 1974;2:81-4.

${ }^{5}$ De Renzi E, Nichelli P. Verbal and non-verbal shortterm memory impairment following hemispheric damage. Cortex 1975;11:341-54.

- Green DM, Swets JA. Signal Detection Theory and Psychophysics. New York: Wiley, 1966.

${ }^{7}$ Buschke $\mathrm{H}$. Selective reminding for analysis of memory and learning. J Verb Learn Verb Behav 1973; 12:543-50.

${ }^{8}$ Buschke H, Fuld PA. Evaluating storage, retention, and retrieval in disordered memory and learning. Neurology (Minneap) 1974;24:1019-25.

${ }^{9}$ Raven JC. Standard Progressive Matrices: Sets ABCD and $E$. London: AK Lewis, 1958.

${ }^{10}$ Roy SN, Bose RC. Simultaneous confidence interval estimation. Ann Math Stat 1953;24:513-36.

" Cartlidge NEF, Shaw DA. Head injury. Lavenham (England): Saunders, 1981:145-54.

12 Ommaya AK, Gennarelli TA. Cerebral concussion and traumatic unconsciousness: Correlation of experimental and clinical observations on blunt head injuries. Brain 1974;97:633-54.

13 Jane JA, Rimel RW. Prognosis in head injury. Clin Neurosurg 1982;29:S15-21.

14 Rowe MJ III, Carlson C. Brainstem auditory evoked potentials and postconcussion dizziness. Arch Neurol 1980;37:679-83. 
${ }^{15}$ Noseworthy JH, Miller J, Murray TJ, Regan D. Auditory brainstem responses in postconcussion syndrome. Arch Neurol 1981;38:275-8.

${ }^{16}$ Schoenhuber R, Bortolotti P, Malavasi P, Marzolini S, Tonelli L, Merli GA. Brainstem auditory evoked potentials in early evaluation of cerebral concussion. $J$
Neurosurg Sci 1983;27:157-9.

${ }^{17}$ Langfitt TW, Gennarelli TA. Can outcome from head $Z$ injury be improved? J Neurosurg 1982;56:19-25.

${ }^{18}$ Rimel RW, Giordani B, Barth JT, Jane JA. Moderate head injury: Completing the clinical spectrum of brain trauma. Neurosurgery 1982;11:344-51. 